\title{
Tongue Entrapment in a Plastic Bottleneck
}

\author{
Ram Rajmani Singh, ${ }^{1}$ Nikesh Meghji Gosrani, ${ }^{1}$ Tejal Patel, ${ }^{1}$ Khitij Dhaval Shah ${ }^{1}$
}

\begin{abstract}
$\underline{\text { Introduction }}$
Oral foreign bodies and perioral injuries are common occurrence among paediatric population. These may range from benign occurrences to those that may threaten the airway. One such injury is tongue entrapment into objects like plastic bottle neck. Tongue entrapment in bottle neck is rare with very few cases reported in literature.

\section{Case Report}

A case of a 9-year old mentally retarded male child with tongue haemangioma who got his tongue tightly entrapped inside a plastic bottle neck is presented. Since such cases are very rare, treatment often requires creative and novel approach to ensure safe removal of constricting object without causing any injury to surrounding structures. When conventional methods using Mayo's scissors failed to cut open the bottle neck, we used Gigli saw wire in a safe manner to cut it open. It took a few minutes to relieve the entrapment of tongue without traumatising the surrounding structure.

\section{Discussion}

This case highlights the result of careless and often dangerous play and misadventures of children and the challenge of management. It calls for vigilance and close supervision of children by caregivers at home and at school. Early presentation, immediate intervention and treatment can prevent grave consequences.

Keywords

Tongue Entrapment; Child
\end{abstract}

ABSTRACT

$\mathrm{P}$ eri-oral injuries are common findings in paediatric patients, and they may have significant medical, dental and psychological consequences in the affected children. ${ }^{1}$ One of such injury is entrapment of tongue within objects. Young children have been known to put their tongue in to many weird and dangerous objects. Tongue entrapment within such objects in not common. ${ }^{2}$ There are very few reports of tongue injury from tongue entrapment in bottles ${ }^{3,4}$ and $\mathrm{can}^{5}$ in the literature. Thus, emergency medical personnel do not have established protocols for treating this life endangering occurrence. ${ }^{6}$

We are reporting a case of 9 years old male child with tongue haemangioma who had tongue entrapment within the neck of a plastic bottle.

1 - Department of ENT, Lokmanya Tilak Muncipal General Hospital and Medical College, Sion, Mumbai

\section{Corresponding author:}

Dr Ram Rajmani Singh

email: ram160286@gmail.com

\section{Case report}

A 9 year old male child presented to emergency department of our hospital after getting his tongue stuck inside the neck of a plastic bottle due to vacuum effect. His parents made multiple attempts to remove it by traction but they couldn't remove it, instead it lead to further tongue oedema and tongue got trapped more firmly. (Fig. 1) Child was then taken to a nearby hospital where base of the bottle was cut and removed. However, they could not remove the bottle neck off the tongue. Due to further increase in tongue oedema, child was referred to our hospital for further management.

On examination, child was restless and crying in pain with excessive sweating and drooling. Vital signs were within normal limits. Child was not in respiratory distress. The anterior half of the tongue was trapped within the neck of a plastic bottle. It was massively oedematous and cyanotic. Immediately intravenous analgesic to relieve pain and intravenous hydrocortisone were given to reduce oedema. 


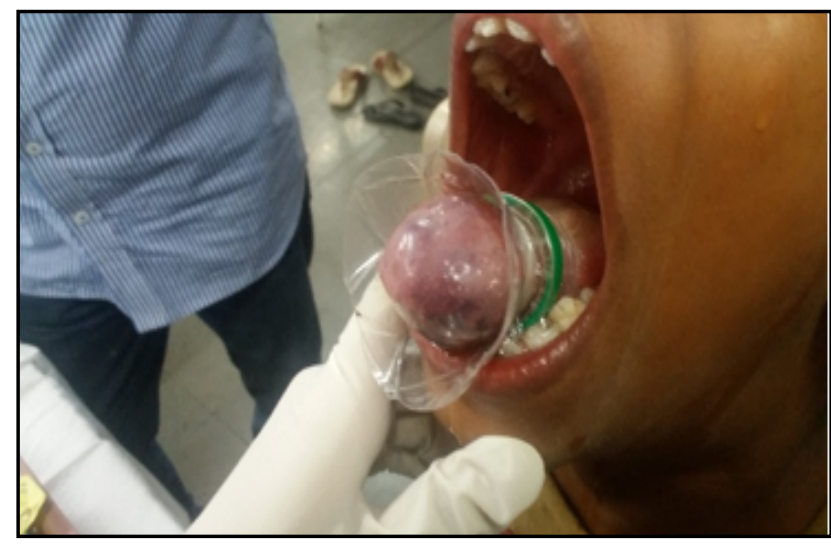

Fig.1. The entrapped tongue

Past history revealed that child had tongue haemangioma on left side of dorsum of the tongue since birth. Keeping this in mind, after holding the child, we made attempt to cut open the neck of the bottle with strong Mayo's scissors. But, Mayo's scissors could not cut through the neck of the bottle. As the oedema was increasing, we planned to take the child under intravenous sedation in the operation theatre. We planned to use a Gigli saw for sectioning the neck of the plastic bottle.

Child was shifted to operation theatre. His airway remained stable and spontaneous respiration was supported with oxygen via nasal prongs. Child was taken under intravenous sedation with ketamine and Glycopyrrolate. A Gigli saw wire taken and its one end passed under the neck of the bottle through the minimal space between tongue and neck of the bottle. In order to prevent trauma to the tongue from Gigli saw wire, a Bard Parker handle was inserted between the wire and tongue. The wire was attached to two Gigli saw handles and moved back and forth few times and bottle neck got sectioned in about 10 seconds. Gigli saw and Bard parker handle were removed. Two cut edges of the bottle neck were retracted apart and taken out with no trauma to the adjacent part of the tongue. (Fig. 2) Entire procedure took less than 10 minutes including sedation.

Anterior half of the tongue was massively oedematous. However, this returned to normal in 5-6 hours. Child was given intravenous dexamethasone, amoxicillinclavulanic acid, analgesic and regular warm salt water gargles. Child observed in the ward for 24 hours and

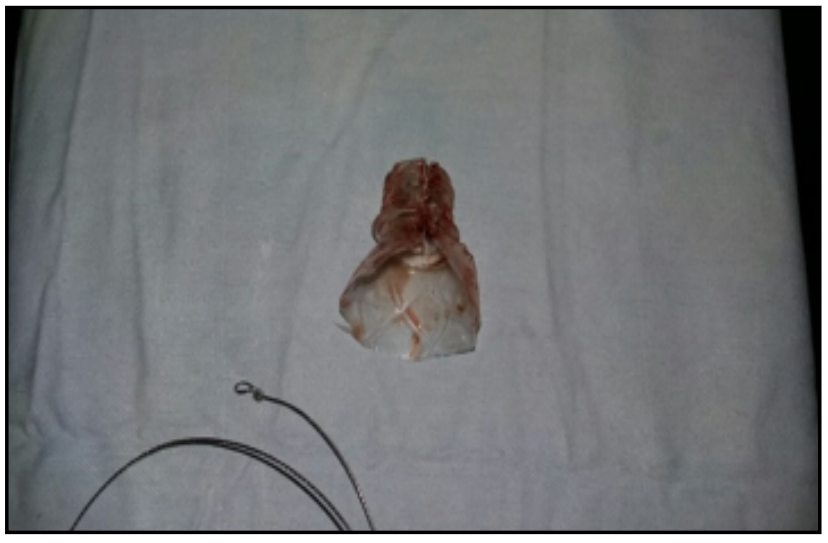

Fig. 2. The bottle-neck after removal

discharged on the next day.

\section{Discussion}

In injury to the tongue, the most common location is the dorsum of the anterior $1 / 3 \mathrm{rd}$. $^{7,8}$ This is also the site in this reported case. The age of our patient is also within the commonly affected age group involved in oro-facial tissue injury. ${ }^{7,9}$ The tongue on presentation was massively oedematous because of impaired venous return due to constriction by the neck of the plastic bottle. The tongue expands after it passes through the neck of the bottle, and when the child attempts to pull his or her tongue out, air is sucked in and a vacuum like seal farther confines the tongue inside the bottle. ${ }^{2,6,4,10,11}$

In this case we tried using conventional methods to cut open the bottle neck with scissors, but it was not possible to do so. So we planned to use a Gigli saw wire to section it. It took around 10 seconds to cut it with the wire. Hence it is a time saving method without any complications if performed correctly with proper assistance.

\section{References}

1. Rothman DL. Pediatric orofacial injuries. J Calif Dent Assoc. 1996; 24(3): 37-42

2. 2 Shah G, Sciarrino J, Barth P, Cook S, O'Reilly R. Tongue entrapement in aluminium waterbottle: discussion of removal and airway management. Int J Pediatr Otorhinolaryngol. 2012; 76: $757-60$ 
3. Green DC. Bottleneck entrapment of the tongue. Otolaryngol Head Neck Surg. 1995; 113(4): 508-9

4. Guha SJ, Catz ND. Lingual ischemia following tongue entrapment in a glass bottle. J Emerg Med. 1997; 15(5): 637-8

5. Bank DE, Diaz L, Behrman DA, Delaney J, Bizzocco S. Tongue entrapment in an aluminium juice can. Pediatr Emerg Care 2004; 20(4): 242-3

6. Gorman A, Potential dangers lurk in water bottles. available at abclocal.go.com/wpvi/story?section=news/special_ reports\&id=7748011.Accessed January 14, 2015.

7. Shulman JD. Prevalence of oral mucosal lesions in children and youths in the USA. Int J Paediatr Dent. 2005; 15(2): 89-97
8. Lamell CW, Fraone G, Casamassimo PS, Wilson S. Presenting characteristics and treatment outcomes for tongue lacerations in children. Pediatr Dent. 1999; 21(1): 34-8

9. Bankole OO, Fasola AO, Denloye OO. Oro-facial soft tissue injuries in Nigerian children: a five-year review. Afr J Med Med Sci. 2004; 33(2): 93-7

10. Fernandes VT, Ng E, Campisi P. Metal water bottle causing tongue entrapment in a child. CMAJ 2014; 186:1091

11. Whited CW, Rocke DJ, Lee WT. Tongue entrapment in metal drinking bottle. Arch Otolaryngol Head Neck Surg. 2011; 137:625-7. 